\title{
GOBERNANZA Y DESBUROCRATIZACIÓN: DEL CONFLICTO ANTAGÓNICO A LA VISIÓN ESTRATÉGICA
}

\author{
Saúl J. Pratts Ponce de León'
}

\section{Resumen}

El artículo provee una visión general sobre el problema de la gobernabilidad en Puerto Rico, que implica la incapacidad e ineficiencia para dirigir al país. Este problema es más profundo que una pobre calidad de la política pública y de desempeño gerencial. Tiene unos aspectos inherentes del modelo burocrático y la politización del gobierno. Un hallazgo principal se relaciona a como la administración pública es parte del proceso político partidista para, mediante la centralización del presupuesto y las decisiones, asegurar el poder. Además, el rol protagónico del gobierno es una rémora para promover un gobierno eficiente. El artículo recomienda que en Puerto Rico se desarrolle una relación diferente entre la ciudadanía, el sector privado y el público, que promueva un cambio en la administración pública tradicional y su diseño organizativo. Se propone el enfoque de gobernanza organizado en redes, ya que el mismo es uno flexible, de colaboración que facilita el consenso entre diferentes sectores. [Descriptores: gobernabilidad, burocracia, nueva gerencia pública, neoliberalismo, gobernanza].

\section{Abstract}

This article provides an overview of the governability problem in Puerto Rico, which implies the incapacity and inefficiency of the government to lead society. This problem is deeper than a poor public policy and lower institutional performance. It involves inherent issues of the government

${ }^{1}$ Catedrático Escuela Graduada de Administración Pública, Universidad de Puerto Rico, Recinto de Río Piedras. 
bureaucratic model and its politization. A primary finding is that public administration is the right hand of politicians to preserve power through the centralization over the public budget and decisions. Other data is that the government as a principal protagonist have became unacceptable and a main concern to promote good governmental performance. The article suggests developing in Puerto Rico a different type of interaction between citizens, private and public sector that contributes to change the traditional public administration ideas and organizational design. The governance approach is a flexible model of governing based on collaboration, consensus in a network organization. [Keywords: governability, bureaucracy, new public management, neoliberalism, governance].

\section{Introducción}

Uno de los asuntos medulares que está bajo continua discusión, tanto en Puerto Rico como en otros países, es la distinción entre el ámbito del sector público y el privado. Por un lado, el liberalismo postula que el gobierno no debe intervenir cuando se trata de la propiedad privada y la libre competencia. De otro lado, se plantea que el gobierno tiene que intervenir regulando al sector privado y ser un proveedor de servicios a la ciudadanía (Keynes, 1936).

La necesidad de la intervención del gobierno se fundamenta en que defiende el bienestar general y es un instrumento de justicia social y de redistribución de riquezas. Entendiendo el bienestar general, como la aspiración de equidad y de servicios donde la necesidad y no la capacidad económica sea el criterio de acceso a bienes y servicios que promueven calidad de vida. Por tanto, se acepta la necesidad de la intervención del gobierno en todas aquellas decisiones y fenómenos que tienen impacto en la vida social y económica del colectivo.

El que se acepte la intervención gubernamental no significa que tengamos que tolerar la ineficiencia. Veamos ejemplos en el sector de la infraestructura. Analicemos las expresiones del Presidente de la Asociación de Navieros sobre la Autoridad de Puertos para usarlo como punto de partida para examinar lo que está sucediendo en Puerto Rico. Nos dice: "Llevamos los últimos 20 años con 16 Directores diferentes en la Autoridad. Eso nos hace lucir muy mal. Eso rompe con la continuidad. Todo se paraliza" (Santiago Caraballo, 2012). 
Estas expresiones dejan al descubierto un funcionamiento gubernamental sin visión de largo plazo, la ausencia de un plan estratégico que guie y le dé continuidad a las acciones de todos los administradores. Deja al descubierto la ausencia de autonomía administrativa que debe tener toda corporación pública y la debilidad de las juntas de directores. Estas condiciones, en esta y otras agencias denotan como la gestión de lo inmediato nos ha quitado la capacidad de imprimirle dirección de futuro al país.

Otro ejemplo de ineficiencia gubernamental lo encontramos en la poca capacidad de innovación. La innovación es la dimensión más importante para las sociedades contemporáneas. Es implantar ideas que agregan una nueva dimensión de valor si se implanta en tiempo razonable. Veamos dos ejemplos: 1) El transporte colectivo mediante el tren urbano tardó unos 40 años desde concebido hasta realizado; 2) La ley 171 de 11 de agosto de 2002 establece la corporación pública conocida como la Autoridad del Puerto de las Américas que se convertiría en el motor para el desarrollo socio económico de toda la región sur. Acaban de pasar 10 años y no se ven barcos de hondo calado dando transferencia de carga, ni una zona de trasbordo internacional, ni una zona industrial de valor añadido, etc. Algo similar está pasando con el desarrollo de la antigua base de Roosevelt Road.

Debemos preguntarnos: ¿por qué el gobierno es ineficiente? ¿Tiene que ser ineficiente? La respuesta es que no. Vemos el caso de Singapur donde el gobierno tiene una administración pública con una estructura organizativa flexible que apoya planes estratégicos. La administración pública es eficiente, con los mejores talentos reclutados por mérito, salarios comparables o superiores a la empresa privada y corporaciones públicas con Juntas de Directores seleccionadas a base de peritaje con procesos de rendición de cuentas y transparencia (Quah, 2010).

En Puerto Rico, se cumplen 70 años desde que Rexford G. Tugwell diseño e implantó una administración pública innovadora. Esta logró combatir la crisis económica que padecimos durante la Segunda Guerra Mundial y orientó el desarrollo económico (Goodsell, 1978). 


\section{Base teórica del modelo prevaleciente}

Para examinar la capacidad del gobierno de Puerto Rico tenemos que analizar algunos principios teóricos. En términos generales, por varias décadas, existió un consenso de ideas sobre tres aspectos medulares: la naturaleza de la administración pública; la naturaleza del Estado, y la forma de diseñar la organización gubernamental. Es decir, que en el mundo académico se logró una aceptación general sobre la administración pública y como debía ser practicada.

El consenso logrado se basó en las premisas formadas para crear una organización capaz de atender las necesidades de la lógica del capitalismo y la emergente sociedad industrial. A principios del siglo $\mathrm{XX}$, las teorías y premisas de los trabajos de Frederick Taylor, Henri Fayol, Max Weber, y Woodrow Wilson se establecen para formar una cultura burocrática. Las ideas centrales según Walsh y Stewart (1992) sobre los actos de gobernar y administrar se resumen en cinco:

1. La autosuficiencia- El gobierno tiene toda la capacidad para elaborar e implementar con éxito política pública y programas para dirigir la economía y la sociedad.

2. El control directo- La estructura de autoridad basada en jerarquía tiene como supuesto que el tope de la pirámide es quien piensa y ejercer el control y la dirección.

3. La rendición de cuentas ascendentes- La rendición de cuentas es de los funcionarios de carrera hacia arriba hasta vincularse al sistema político, no a la sociedad.

4. La uniformidad - El prototipo de servicios tenía que estar disponible a todos por igual.

5. La estructura burocrática- Diseño organizativo basado en jerarquía de autoridad centralizada y formal, reglas y procedimientos uniformes, división de tareas, sin participación de empleados y ciudadanos. Su trasfondo proviene de las instituciones militares y eclesiásticas.

El sociólogo alemán Max Weber estableció que el diseño de autoridad centralizada y jerárquica aseguraba que al interior se diera un proceso racional de decisiones. Los empleados eran por naturaleza incapaces de ser disciplinados y de no ofrecer el máximo, por lo que hace énfasis en la jerarquía de autoridad y de reglas para prescribir orden en el trabajo. Por tanto, son los elementos de control y disciplina los que aseguraban la 
eficiencia y confiabilidad de la organización. Este modelo ubica al sector público con autonomía de la sociedad y en su interior predomina la racionalidad en su organización y funcionamiento. En este sentido se establece una diferencia entre la función de liderato político y la ejecución de la burocracia profesional. La cual es realizada por unos empleados de carrera reclutados por sus méritos y aislados de los sistemas y estructuras políticas.

Varios tratadistas, entre ellos Woodrow Wilson, condenaron la intromisión partidista al valorar la neutralidad política. Para él, la base de una gestión pública exitosa es la separación de la administración pública del sistema político. Esta premisa de despolitización tiene dos vertientes; primero, la no intromisión partidista sobre las decisiones de interés público y segundo, que la administración pública sea un cuerpo profesional que no sea impactado por el vaivén o cambios de partidos en el gobierno. Son reconocidas las limitaciones reales de implantar las ideas de Max Weber y Woodrow Wilson sobre la separación de la política de la administración.

Herbert Simon desarrolló para los años de 1940 en sus trabajos sobre administración pública la teoría de cómo las organizaciones y la conducta humana tienen la capacidad de tomar decisiones inteligentes, aún cuando los seres humanos son limitadamente racionales. Una de sus ideas de mayor relevancia para la administración pública fue la relacionada a la formulación de la política pública. Esta al orientarse por la racionalidad limitada lleva a que los protagonistas o gobernantes tiendan a buscar soluciones satisfactorias más que a optimizar los resultados. Para Simon (1947), el liderazgo se ejerce a partir de la calidad del conocimiento, por eso la importancia del peritaje ya que fomenta reconocer la información que es relevante y se aumenta la capacidad de ver lo invisible. En esta dirección el pensamiento de este autor es de impacto al reclamarle a los formuladores de política pública y a los administradores que sus valores y su ideología no predominen sobre los hechos, sobre la realidad y en la gestión de solucionar los problemas (Simon, 1947).

Las virtudes y limitaciones de este modelo de organización burocrática han sido fuente de pensamiento como la de las relaciones humanas. Sin embargo, los principios de la administración científica y de la teoría clásica continuaron vigentes en la práctica de una administración pública basada en 
el modelo burocrático durante el siglo XX, del cual Puerto Rico no fue la excepción.

En Puerto Rico, este modelo de gobernar, centralizadoautoritario con diseño burocrático ha estado vigente y reforzado por elementos históricos. El sistema militar español promovió una cultura política y administrativa centralizada en el Ejecutivo y un nivel municipal dirigido por un Teniente de Gobierno, que ahora es el alcalde. Este esquema se reproduce bajo el régimen militar estadounidense y es el modelo en las leyes Jones y Foraker. En la década de 1940, el gobernador y diseñador de nuestra administración pública, Rexford G. Tugwell fortaleció y logró institucionalizar el nivel central como mecanismo de control de la gestión pública, principalmente en la figura del gobernador.

Por eso hemos sido condicionados como ciudadanos a permitir y hasta alentar unos estilos autoritarios de gobernar, promover la cultura del jefe y la idea de que el gobierno es el responsable de todo. En resumen, se ha institucionalizado que el gobierno es el protagonista que está encargado de pensar y ejecutar. Por su parte, al ciudadano se le condiciona a que asuma un rol pasivo de espectador ante las acciones gubernamentales.

\section{El problema de la ingobernabilidad}

Nos preguntamos: ¿Por qué se le agotó a este modelo la capacidad administrativa, directiva, fiscal y política de ofrecer respuestas a las necesidades y expectativas de la ciudadanía? A finales de los años de 1960, Peter Drucker usa el término ingobernable como una posibilidad real ante la falta de control sobre las políticas públicas e ineficiencia del sector público para resolver problemas (Drucker, 1963 y 1989). Este término, posteriormente la literatura (Cozier, Huntington, \& Watanuki, 1975) lo incluye bajo el debate del problema de la gobernabilidad vs. la ingobernabilidad. Para Aguilar (2007), "gobernabilidad denota la posibilidad o probabilidad de que el gobierno gobierne a la sociedad, mientras su opuesto, ingobernabilidad, significa la posibilidad o probabilidad de que el gobierno deje de gobernar a su sociedad o no la gobierne" (p.13). Por tanto, la gobernabilidad es un asunto planteado a tres niveles del gobierno:

1- Tener la capacidad para formular una visión de país que le ofrezca dirección. 
2- $\quad$ El formular políticas públicas relevantes que respondan a las exigencias de desarrollo económico y social.

3- Tener una organización de alto rendimiento con gran capacidad operacional para producir resultados.

Para explicar la ingobernabilidad se han planteado factores internos al modelo burocrático que lo hacen obsoleto y factores externos de cambios en la sociedad y en la economía donde el modelo no tiene la capacidad de adaptación y flexibilidad para responder. Entre los factores internos se destaca la premisa de que toda la información relevante para tomar decisiones está en la cúpula cuando al momento todos los niveles tienen información clave para tomar decisiones. Con el agravante que no se tienen mecanismos de comunicación y participación con empleados y la ciudadanía. La premisa de las reglas escritas llevó a la sobre reglamentación que no permite responder rápidamente a cambios y a nuevas exigencias. La premisa de la división de tareas y los procesos fragmentados que aumentan costos y dificulta introducir nueva tecnología para acelerar los resultados.

El modelo tiene como premisa de funcionamiento eficiente una sociedad estable y una economía nacional-territorial que deja de existir ante las nuevas condiciones que emergen de la globalización de la economía mundial. Según Drucker (1989), desde los años de 1960 ocurre la transformación de cuatro dimensiones que estaban produciendo una discontinuidad social y la obsolescencia del modelo burocrático debido a su rigidez. Las dimensiones son las siguientes:

1- La revolución tecnológica como determinante en el sistema de producción.

2- $\quad$ La integración de los procesos de producción, consumo y financiamiento a nivel mundial.

3- El pluralismo ideológico como fundamento de la realidad sociopolítica.

4- El conocimiento como el recurso central de la economía en sustitución de la materia prima y el trabajador manual.

Aguilar (2007) señaló seis factores que contribuyeron al colapso del modelo. Los mismos son los siguientes:

1- Las distintas crisis financieras de los años 80 rompen con la idea de que el gobierno era fuente de desarrollo, sostener beneficios a la ciudadanía, bienestar social y 
se percibe como de desgobierno.

2- El proceso de globalización de la economía y el poder de los mercados internacionales le restó poder al gobierno de regular y dirigir el crecimiento económico en su propio territorio.

3- La complejidad del sistema social que se ha convertido en subsistemas diferenciados que interactúan entre sí cada uno con sus propios códigos.

4- La creciente fortaleza de los grupos sociales y económicos organizados que han dejado de recurrir al poder público para asegurar su bienestar.

5- Aumentó la percepción de políticas públicas desarticuladas, servicios ineficientes con trámites excesivos y lentos.

6- Desilusión y descontento con la poca capacidad directiva en cuanto a la desigualdad social y seguridad.

En resumen, las transformaciones ocurridas lograron la ruptura de las premisas y realidad de la era industrial que nos ha llevado a la era del conocimiento y a un nuevo orden económico socavando las condiciones y relevancia de la organización burocrática. Es de aceptación general que la estructura burocrática centralizada, piramidal y su concomitante cultura del jefe han quedado rezagadas ante las nuevas circunstancias. Esto constituye un factor clave en crear la condición de ingobernabilidad. La empresa privada fue también atrapada por el burocratismo. Estas, ante la presión del mercado y la rentabilidad, se transformó hacia nuevas formas de organización como la de matriz, estructuras achatadas a base de procesos de trabajo y otras para poder sustituir el modelo burocrático y lograr mayor eficiencia y rentabilidad.

\section{Las respuestas al problema de capacidad directiva}

Al romperse la ecuación de que la acción del gobierno equivalía a darle dirección a la sociedad el mundo académico empezó desde la década de los 1970 a buscarle solución a la ingobernabilidad. Ante los diversos contextos surgieron diferentes respuestas en cada país. La interpretación del rol del gobierno, su diseño y relación con otros sectores externos se convirtieron en fuente de diálogo constructivo.

El académico Luis F. Aguilar considera que la búsqueda de respuesta produjo dos enfoques: la gobernabilidad y la 
gobernanza. La gobernabilidad tiene el propósito de dotar al gobierno de las capacidades para poder dirigir de forma eficaz a la sociedad. Este enfoque centrado en las capacidades del gobierno no cambia el patrón tradicional de dirigir la sociedad y que su desarrollo es el resultado de las acciones del gobierno. Para él, este enfoque considera "que un gobierno bien equipado con los recursos y poderes apropiados es suficiente para dirigir la sociedad" (Aguilar, 2007, p.16).

De acuerdo con unos académicos italianos (Fattore, Dubois \& Lamenta, 2012), la administración pública entró en un proceso de reformas recogido bajo dos términos sombrillas: la nueva gerencia pública y la nueva gobernanza pública. Para los autores, la nueva gerencia pública sirvió de transición al enfoque de nueva gobernanza pública. Según estos, la nueva gerencia pública incluyó teorías gerenciales y el neoliberalismo como forma de reformar el gobierno. Es una ruptura con las teorías de las ciencias políticas en favor de la gerencia organizacional y el mercado. Para los autores, la gobernanza incluye distintas formas de interacción entre gobierno, sector privado, sociedad y grupos no gubernamentales.

Vemos como la tendencia moderna es plantear a la gobernanza como el enfoque dominante en estos momentos. En términos generales, para propósito de análisis agrupamos en cuatro las respuestas a la ingobernabilidad. Las cuales han estado o pueden estar presentes o combinación de ellas en un mismo momento para atacar la ingobernabilidad.

\section{1- Reorganización y renovación dentro del gobierno}

La reorganización y renovación burocrática enfatizan los aspectos de la estructura administrativa. Una de las propuestas de mayor acogida fueron las diversas modalidades de la descentralización. Estas son la desconcentración, la devolución y la delegación. (Cheema \& Rondinelli, 2007) El uso de la descentralización tenía el propósito de mejorar las decisiones para acelerar el desarrollo económico, aumentar la participación ciudadana, eliminar la ineficiencia y atender los asuntos particulares con prontitud. Otras modalidades de reorganización de la estructura administrativa fueron dirigidas a la creación de departamentos sombrillas, consolidar agencias, centros de gestión única, leyes de ocaso, grupos interagenciales y reformular las funciones. 


\section{2- La nueva gerencia pública}

Está centrada en modificar la forma tradicional de cómo funcionan las operaciones del gobierno. Se basa en cambiar los métodos, técnicas operacionales y principios por los de la gerencia empresarial bajo la premisa de que aumentaría la productividad del empleado y mejoraría el desempeño operacional y la eficiencia fiscal. Esto implica el uso de diversos métodos y técnicas de acuerdo a la situación. Algunos ejemplos fue el formular planes estratégicos, la reingeniería de los procesos, incorporar la filosofía de calidad total, six-sigma, presupuesto base cero o por programas, desarrollo de indicadores de ejecución, evaluación programática, auditorias, bonos de productividad, evaluación por desempeño y otros.

Estos desarrollos teóricos y prácticos llevados al sector público, promueve que la administración pública utilice criterios de costos y de calidad en la toma de decisiones y en las evaluaciones. Esta reformulación se recoge bajo los enfoques de gobierno empresarial y la nueva gerencia pública (Osborne \& Gaebler, 1992). El impacto de esta tendencia llevó al planteamiento de que la administración pública y la privada deben ser similares en su funcionamiento. Es decir, que la propuesta para retomar la gobernabilidad se basó en adoptar prácticas gerenciales del sector privado. Este enfoque, al limitarse a los aspectos operacionales, dejó intactas las limitaciones estructurales y encontró la resistencia de la lógica burocrática en la implantación y desarrollo exitoso de estas técnicas gerenciales. Además, se trasplantaron sin analizar el contexto político y propósito de la administración pública.

\section{3- El neoliberalismo}

Para la década de 1980 resurge, para superar la vulnerabilidad fiscal del gobierno, la argumentación neoliberal que crea la dicotomía entre empresa y gobierno. Su premisa es que la sociedad necesita un gobierno pequeño en tamaño y dominio que promueva aumentar el rol de la empresa y el libre mercado. Por tanto, sus principales estrategias son: reducir el tamaño del gobierno, retirarlo como proveedor directo de servicios y desreglamentar al sector privado (Friedman, 1962). 
En varios países esta estrategia se materializó en una combinación de la venta de todos o parte de los activos de empresas públicas rentables, la contratación o subcontratación de actividades a grupos privados, retiro del gobierno como proveedor directo traspasándolo al sector privado y el desarrollo de proyectos entre el gobierno y la empresa privada. A diferencia de las propuestas anteriores, el neoliberalismo es un cambio a la filosofía y modo de gobernar.

\section{4- La gobernanza como nuevo proceso directivo}

La premisa de la gobernanza es que la complejidad, realidades y dinámicas socioeconómicas rebasan la capacidad de respuesta de un gobierno protagonista, que se ha tornado necesario, pero insuficiente. Por eso surge este cuarto enfoque dirigido a establecer un nuevo proceso directivo. El enfoque se ha generalizado al punto que las Naciones Unidas lo definen como las "Instituciones y procesos a través del cual el gobierno, la sociedad civil y el sector privado interactúan en dar forma a la política pública a través del cual los ciudadanos articulan sus intereses, median sus diferencias y ejercen sus derechos" (United Nations Development Program, 1990, p.9). Por eso el enfoque no es antigubernamental, sino un enfoque que Peters (1970) lo plantea a dos niveles. Primero, un nuevo proceso directivo con un nuevo modo de gobernar que le da dirección a la sociedad. Segundo, reformula el rol que asumen los distintos sectores al interactuar con el gobierno. Por tanto, es una nueva forma sobre cómo establecer las metas de la sociedad y los medios para lograrlas, dejando atrás al gobierno como protagonista.

El enfoque está centrado en una total apertura al ambiente externo al gobierno. Como concepto sombrilla abarca distintas modalidades. Una de ellas es la que se recoge bajo buena gobernanza. La estrategia está basada en implantar mecanismos de transparencia y de rendición de cuentas que terminen con la práctica gubernamental del hermetismo de la información (Ferranti, 2009; Torres \& Pratts, 2003). Su base teórica está en la sociología de las organizaciones y en diseño organizativo de redes. Su énfasis es el pluralismo de ideas añadiendo recursos que están fuera del gobierno. Para su implantación se sustituye la jerarquía de autoridad por la capacidad de pertenecer, aportar ideas, 
dialogar y la negociación basada en conocimiento y peritaje en un esquema horizontal.

La nueva tendencia promueve un estilo de gobernar inclusivo, sin el protagonismo del gobierno. En el mismo participan múltiples sectores y el diseño organizativo dependerá de las particularidades del país y del asunto a tratarse. Por eso, la gobernanza se adapta a las realidades sociales. Estas definen como se entrelazan, comunican e interactúan los distintos sectores para gestionar los asuntos públicos mediante participación real y tomar decisiones por consenso. Por eso, una de sus virtudes es la flexibilidad o capacidad para adaptarse a diferentes situaciones y contextos.

\section{Puerto Rico ante la ingobernabilidad}

En Puerto Rico, desde la década del 1970, la clase dirigente del país ha estado consciente de la ingobernabilidad que padecemos. Se han realizado esfuerzos y las cuatro respuestas mencionadas han estado presentes en Puerto Rico. En esa década el gobernador Rafael Hernández Colón planteó: "Una de mis preocupaciones mayores desde que asumí la gobernación ha sido la búsqueda de alternativas para bregar con la problemática de la burocratización de nuestro gobierno" (Entrevista a Rafael Hernández Colón, 1976, p. 139).

Estas expresiones recogen un planteamiento del gobernador Hernández Colón para su primer cuatrienio de gobernación, que continúan vigentes. La solución al problema se dirigió a la necesidad de "reducir el número de organismos públicos; revisar y simplificar toda esa maraña de procedimientos y trámites de la burocratización de nuestro gobierno" (Entrevista a Rafael Hernández Colón, 1976, p. 139) Ante esta condición, su administración realizó varias gestiones de renovación dentro del gobierno, como una reorganización de la Rama Ejecutiva. El propósito fue reducir el número de agencias que respondian directamente al Gobernador y desde el 1973 intensificó el estudio y revisión de procedimientos y normas para acelerar la prestación de servicios. La otra acción fue dirigida al nivel de formulación de política pública. Esta fue la creación de los Talleres del Nuevo Puerto Rico para que la política pública fuese integrada y coordinada.

En su segunda administración-1985 al 1992- creó los Consejos de Gobierno en el 1985. Los cinco consejos se organizaron por los Directores de Agencias en función de los 
objetivos principales del gobierno.: 1- empleo a corto plazo, 2empleos a largo plazo, 3- educación y cultura, 4-salud y bienestar y 5 - seguridad pública. El propósito era que los Secretarios discutieran de forma integrada la idea y la implantación de la política pública (El Nuevo Día, 10 de noviembre de 1985).

Esta definición como un problema que surge debido al tamaño del gobierno y de procesos ineficientes es la base de los estudios sobre la Reorganización de la Rama Ejecutiva de 1949, 1971, 1976 y 1980. Si hoy continuamos con la misma situación se debe a que esta definición no cuestionó las premisas y el diseño de organización burocrática. Es decir, que se dejó intacta la verdadera causa, que es la total obsolescencia y colapso del modelo burocrático que define nuestra estructura de gobierno. Por eso, a medida que pasa el tiempo se hace más evidente la ingobernabilidad.

Rafael Hernández Colón, bajo la estrategia de reorganización, aprobó dos medidas dirigidas hacia la descentralización. Una de ellas fue la Reforma Municipal de 1991 y la otra, la Compañía para el Desarrollo de la Península de Cantera. La reforma municipal se planteó como una forma de iniciar un proceso de renovación político y administrativo del gobierno municipal con tres objetivos- la transferencia de poderes, la reforma administrativa y el logro de autonomía fiscal. Lo crítico de la municipalización fue que no rompió con el modelo burocrático y no consideró las grandes diferencias económicas, gerenciales y fiscales que existen entre ellos. En términos generales, no pasan de una docena los municipios con capacidad para añadir funciones de manera exitosa (Pratts, 2009). El proceso no tuvo continuidad ya que en enero de $1993 \mathrm{el}$ nuevo gobernante introduce otra visión ante la ingobernabilidad. Por eso inmediatamente, las leyes de Reforma Municipal fueron enmendadas en 38 ocasiones limitando la autonomía fiscal y los planes de ordenamiento territorial.

La segunda medida hacia la descentralización y estableciendo un diseño de gobernanza es la Ley 20 de 1992 que crea la Compañía para el Desarrollo Integral de la Península de Cantera. La misma plantea en la sección 5001-propósito de la Ley, lo siguiente:

El esfuerzo no puede depender de una particular agencia del gobierno central, ni el gobierno municipal, ni conducirse por éstos 
sin a el apoyo entusiasta del sector privado y sin la inherencia de la comunidad afectada. La experiencia enseña que, en este campo, muchas buenas ideas han sucumbido víctimas de la fragmentación de la autoridad pública, de la centralización y burocratización excesiva...

La Compañía se organizó de manera innovadora en forma de redes entre el sector público, privado y la comunidad. Se estableció una vigencia de 15 años con extensión de 5 . Su reto principal fue formular un plan de desarrollo integral con el propósito del "mejoramiento de la calidad general de la vida de los presentes y futuros residentes...". En el mismo se tenían que incluir dimensiones empresariales, educativas, el tejido social, industriales, producción de empleo como infraestructura, vivienda, facilidades recreativas y otras. Este Plan fue aprobado en 1995 y su implantación ofreció dirección a las once comunidades logrando una transformación en la calidad de vida de sus residentes. Desde el punto de vista de la administración pública se demostró que el estilo de gobernanza y la organización en redes es superior al gobierno burocráticocentralizado.

La gobernación de Rafael Hernández Colón tuvo un énfasis en la estrategia de reorganización y renovación dentro del gobierno. Cabe señalar que tomo acciones neoliberales dirigidas a la privatización como la venta de La Telefónica Larga Distancia. Además, incorporó una modalidad de privatización conocida como alianza público privada. Esta ocurrió en la construcción y administración del Puente Teodoro Moscoso. Este concepto se utiliza para que los países, debido a limitaciones fiscales, añadan infraestructura nueva con capital de la empresa privada. Por eso, esta es la única en Puerto Rico, ya que la transacción de administrar los expresos número 20 y 5 no son alianzas pública privadas al igual que lo propuesto para el aeropuerto Luis Muñoz Marín. Estas son acciones tradicionales de privatizar la administración de servicios gubernamentales que son rentables.

Como mencionamos, se creó una ruptura a la tendencia de descentralizar. A partir del cambio de gobierno en 1993, con la entrada del Dr. Pedro Rosselló, surgió una nueva estrategia ante la ingobernabilidad basada en la nueva gerencia pública y se acentuó el neoliberalismo. Con estos enfoques se 
inicia "la tarea de reestructurar la organización del gobierno, para transformarlo un uno facilitador, y así descartar su rol tradicional paternalista y proveedor de servicios". Para esto se utilizaron estrategias de "fusión, disolución, reorganización, desgubernamentalización, desreglamentación, mejoras en la comunicación, en los procesos, control de empleo y reducción de la burocracia y el gasto público" (Aponte, 2000, prefacio del Dr. Pedro Rosselló).

En la década del 1990, la estrategia de la nueva gerencia pública impactó al gobierno de Puerto Rico. Se inician procesos de reingeniería, evaluaciones por resultados, formular planes estratégicos, calidad total y otras técnicas gerenciales. Estas acciones se enmarcan en la filosofía del neoliberalismo con su premisa de que tanto el tamaño del gobierno como su gestión obstaculizan el desarrollo económico, por lo que se implantaron procesos de privatización y desreglamentación del sector privado. Se estableció un Comité de Privatización para identificar e impulsar proyectos. Los de mayor impacto fueron el traspasar la administración de la Autoridad de Acueductos y Alcantarillados al sector privado, la venta de la Compañía Telefónica y el dejar de ser proveedor directo de salud para contratar a compañías de seguros de salud. Los asuntos críticos de este paradigma y sus acciones son los siguientes:

1- El sector privado exige rentabilidad, ganancias y reducir los riesgos de su inversión. Esto entra en conflicto con reducir los gastos y puede afectar el acceso a los servicios, la capacidad del gobierno de formular la política pública y darle dirección a la sociedad. Por eso la privatización debe ser en áreas marginales que no influyan en la capacidad del gobierno en la formulación de política pública.

2- La desregulación tiene una premisa sobre las bondades y eficiencia del sector privado que no siempre han estado presentes. La desregulación implica falta de controles que han estado relacionados a escándalos corporativos, esquemas de corrupción y conflictos de interés.

Además, las campañas en favor de la privatización sobre-enfatizan las deficiencias organizativas y operacionales del gobierno. Se oculta el valor del gobierno como instrumento 
de justicia social, la necesidad de que conserve la capacidad de formular política pública al margen de los intereses particulares.

Las acciones tomadas por 30 años no lograron producir la transformación del problema de centralización e ineficiencia de la Rama Ejecutiva. En algunos sectores del gobierno la creación de departamentos sombrillas aumentaron la centralización, los niveles de jerarquía y la complejidad de los procesos internos, sin mejorar la calidad de los servicios y reducir los costos. Además, el país sufrió la ineficiencia del sector privado (Compañía de Agua y Ondeo) con la privatización de la Autoridad de Acueductos y Alcantarillados.

Luego de estas acciones de reorganización al interior del gobierno, de nueva gerencia pública y de neoliberalismo hemos tenido por lo últimos doce (12) años un predominio del discurso neoliberal. Los gobernadores anteriores se expresan sobre sobre el problema de la ingobernabilidad. Acevedo Vilá (2006) señala: "El Gobierno, una vez motor del crecimiento, se ha convertido en obstáculo y carga para la economía y tiene que transformarse para convertirse en un facilitador". Por su parte Fortuño (2009), expresa: "Un gobierno más pequeño no solo será menos costos para nosotros los contribuyentes, sino que será más ágil y eficiente".

La clase dirigente del país tiene que evitar continuar definiendo el problema de ingobernabilidad con premisas equivocadas, ya que de esa forma no logra atender efectivamente el problema y pueden recrudecerlo. Es dogmático plantear que el problema es el tamaño del gobierno y que al reducirlo todo mejora aunque se afecten servicios públicos importantes. El tamaño del gobierno tiene que evaluarse sobre bases comparativas. En un estudio a base de los datos del Bureau of Labor Statistics, Alameda (2009) encontró que Puerto Rico en el 2008 tenía una razón de 7.3 empleados públicos y 18 en empleo privado por cada 100 habitantes. Al comparar esta situación con Estados Unidos se evidenció que el $42 \%$ de los estados tienen una proporción mayor de empleados públicos. Esta comparación nos lleva a concluir que la premisa del gigantismo no se justifica, en especial al contar con un amplio estado benefactor. Por otro lado, al comparar con la proporción de empleo privado se evidencia que tenemos con 18 empleados por cada 100 habitantes el indicador más bajo. Esta información presenta el problema real como la pequeñez del empleo en el sector privado.

Si comparamos la situación laboral con una país con 
similar tamaño poblacional como Irlanda, encontramos que en Puerto Rico el $8.04 \%$ y en Irlanda el $8.54 \%$ en relación a la población total son empleados públicos. El análisis realizado por el Prof. Argeo Quiñones indica que los empleados públicos en Puerto Rico representan el $26.3 \%$ del total de empleados, mientras en Irlanda, representan el $15 \%$ del total de empleados (Comunicación personal). La información confirma que Puerto Rico se caracteriza por un sector privado que no genera suficientes empleos.

De todos los esfuerzos para superar la ingobernabilidad, el superior ha sido el modelo de gobernanza implantado en La Península de Cantera. Sus logros y sus lecciones son muy importantes para nuestro futuro. Primero, se organizó de forma horizontal en redes que le permitió añadir recursos humanos, fiscales y eliminar el protagonismo de los políticos. Segundo, su Junta de Directores estaba compuesta por residentes recomendados por el consejo vecinal, personas del sector privado y del gobierno. Esto permitió ser ejemplo de transparencia y autonomía administrativa y fiscal. Tercero, las acciones fueron guiadas , luego de un amplio proceso de participación, mediante un plan estratégico a 10 años, por el cual se tenía que rendir cuentas a la comunidad. Tras 20 años de vigencia podemos concluir que este enfoque logró desburocratizar, despolitizar, repotenciar y enriquecer la gestión pública.

Nos preguntamos ¿por qué en vez de fomentar ese modelo se recrudeció la ingobernabilidad? ¿Por qué no rompemos con el modelo burocrático? ¿Dónde está la resistencia al cambio? Toda acción administrativa tiene lugar en un contexto social particular. ¿Cómo es nuestro ambiente político? De consenso o adversativo. ¿Cómo el gobierno se enfrenta a la incertidumbre del futuro? De forma racional científico o ideológico -valorativo.

El ambiente político-administrativo en Puerto Rico es uno de conflicto antagónico que en vez de promover acciones visionarias a base de conocimiento y peritaje predomina la motivación de adelantar intereses partidistas. Por eso, encontramos que toma más fuerza la ecuación de que el gobierno es para privilegiar a los miembros del partido político que obtiene la gobernación. Este ambiente ha deteriorado al máximo a la administración pública que no ha logrado incorporar medidas de transparencia, rendición de cuentas y medidas anticorrupción que funcionen. 
En Puerto Rico converge una cultura política de intolerancia basada en la politización del sector público y el clientelismo político que necesitan mantener al modelo burocrático. Este modelo le facilita al partido tomar el control sobre la administración pública para cumplir con las expectativas de sus constituyentes, aportadores de la campaña y del clientelismo en general a cambio de lealtad política.

\section{Agenda urgente: Ruptura del paradigma}

Para alcanzar una sana y eficiente administración pública y un mejor futuro tenemos que lograr desburocratizar y despolitizar al gobierno. Esto implica sustituir la cultura del debate por la del diálogo. El debate intenta demostrar que los otros están equivocados porque el correcto soy yo, se le tiene que ganar al adversario y se buscan los defectos de las otras ideas. Por su parte, el diálogo propone encontrar terreno común que sea inclusivo donde todos aportan con sus ideas para lograr entendimiento común y la mejor solución.

En el contexto del diálogo es que se puede atender la exigencia de la ciudadanía de que el gobierno se transforme en uno de alto rendimiento orientado a resultados y abierto a distintas vertientes de pensamiento. Para lograrlo, tiene que adoptarse el enfoque de red de gobernanza (Sorensen \& Torfing, 2003). Este promueve un proceso de pensamiento constructivo basados en la interacción entre: el gobierno, sector privado, tercer sector, academia, sindicatos, industriales, agricultores, y otros.

Estas redes tienen una agenda en tres dimensiones interrelacionadas. Primero, delinear una visión de país y estrategias integradoras. Segundo, mediante el pluralismo de ideas, profesionales y conocedores de distintos sectores tiene que elaborar por consenso acciones específicas para esas estrategias. Tercero, el nivel operacional del sector público tiene que asegurar un desempeño de alto rendimiento, transparencia y rendición de cuentas. Se tiene que sustituir el diseño burocrático y profesionalizar la administración pública.

El lograr una visión de país, el definir unas estrategias y acciones por consenso permiten tener un plan estratégico de país. Esto es una condición necesaria, pero no suficiente para adelantar y desarrollar el país. Se tiene que complementar por un gobierno con capacidad administrativa de alto rendimiento que asegure los resultados deseados. Para esto se tiene que atender 
al menos cuatro asuntos prioritarios: 1) Una reconfiguración comprensiva de la estructura organizativa; 2)Asegurar la autonomía administrativa y fiscal de las Corporaciones Públicas; 3)Redirigir hacia la gobernanza la gestión municipal; y 4) Fortalecer el principio de mérito y la rendición de cuentas.

El rediseño organizativo que necesita la administración pública tiene que realizarse incluyendo el análisis de forma comprensiva de la rama ejecutiva, sus regiones, nuevos esquemas de integración de servicios municipales y los municipios. Su enfoque tiene que ser a base de procesos que permita estructuras horizontales orientadas a resultados. Otra dimensión importante es la de dirigir los esfuerzos para asegurar la autonomía administrativa y fiscal a las Juntas de Directores de las Corporaciones Públicas. El propósito es sacarlas de la motivación partidista y de corto plazo. El gobernador nombraría un tercio de sus miembros de jefes de agencias relacionadas. Los restantes serán electos, por término escalonado, de entre candidatos conocedores o peritos del asunto. Esta Junta tiene que elaborar un plan estratégico a 10 años guiado por la visión de país y anualmente rendir cuentas al país y actuar de forma transparente. La evaluación continua es la base para la remoción de estos miembros de Juntas.

El nivel municipal tiene que rediseñarse de forma horizontal para apoyar una gestión de gobernanza. El modelo actual burocrático-piramidal es contrario a la gestión de gobernanza. Por eso sería un buen inicio implantar el modelo usado en la Península de Cantera en una comunidad. Esto permitiría ampliar el modelo de gobernanza en la administración municipal.

Estos esfuerzos tienen que estar basados en el fortalecimiento del principio de mérito, la transparencia de la información y la rendición de cuentas. El sistema de mérito tiene que iniciarse con un proceso transparente de divulgación de convocatorias, registro de elegibles y de reclutamiento y selección. Su definición operacional es la de realizar pruebas escritas de selección que midan las habilidades del puesto y conocimiento en igualdad de condiciones. Además, la profesionalización del servicio público y el sistema de mérito exige eliminar las instancias de politización que están detrás de los contratos temporeros y los puestos de confianza. 
Este paradigma tiene el propósito de que Puerto Rico, mediante una democracia participativa, se mueva del conflicto antagónico en que nos encontramos a una visión estratégica de consenso que nos transite de restricciones a oportunidades y a una mejor calidad de vida. 


\section{Referencias}

Acevedo Vilá, Aníbal. (2006). Plan de Desarrollo Económico y Transformación Económica. San Juan: Estado Libre Asociado de Puerto Rico.

Agranoff, Robert. (2007). Managing Within Networks: Adding Value to Public Organizations. Washington: Georgetown University Press,.

Aguilar, Luis F. (2007). El Aporte de la Política y de la Nueva Gerencia Pública en Revista CLAD Reforma y Democracia, 39, 7-32.

Alameda, José I. (2009). ¿Es realmente grande el gobierno o es que el sector privado es pequeño? (artículo no publicado).

Aponte, Jorge. (2000). Evolución del Gobierno de Puerto Rico: 19932000. San Juan: Oficina de Gerencia y Presupuesto, ELA.

Bouvard, Tony, \& Loffler, Elke. (2009). Public Management and Governance. London: Routledge.

Cozier, M.ichael; Huntington, Samuel, \& Watanuki, James. (1975). The Crisis of Democracy. New York: University Press.

Drucker, Peter F. (1983). The Age of Discontinuity. New York: Harper \& Row.

Drucker, Peter F. (1989). The New Realities. New York: Harper \& Row.

Drucker, Peter F. (1999). Management Challenges for the 21st. Century. New York: Harper \&

Entrevista a Rafael Hernández Colón. (1976). Revista de Administración Pública, VIII, 135-148.

Fattore, Giovanni; Dubois, Hans, \& Lamenta, Antonio. (2012). Measuring New Public Management and Governance in Political Debate. Public Administration Review, 72 (2), 218-277.

Ferranti, David; Jacinto, Justine; Ody Anthony, \& Ramshaw, Graeme. (2009). How to Improve Governance. Washington: Brookings Institution.

Fortuño, Luis. (2009). Presentación a la Asamblea Legislativa. San Juan: Estado Libre Asociado de Puerto Rico.

Friedman, Milton. (1962). Capitalism and Freedom. Chicago: University of Chicago Press.

Goodsell, Charles T. (1978). Administración de una Revolución. San Juan: Editorial UPR.

Hermes, Georges. (2008). Populismo, Democracia y Buena Gobernanza. España: Ediciones de Intervención Cultural.

Keynes, John Maynard. (1936) The General Theory of Employment, Interest and Money. London: Hartcourt Brace Co.

Kooiman, Jan. (2003). Governing as Governance. London: Sage. 
López Pumarejo, Héctor. (2000). Gobernabilidad y Municipalización. San Juan: Universidad de Puerto Rico.

Osborne, David, \& Gaebler, Ted. (1992). Reinventing Government: How the Entrepreunial Spirit is Transforming The Public Sector. Massachusetts: Adisson-Wesley.

Peters, B. Guy. (2000). The Future of Governing: Tour Emerging Models. Kansas: University Press of Kansas.

Peters, B. Guy. (2007). Globalización, Gobernanza y Estado: Algunas proposiciones acerca del proceso de gobernar. Revista CLAD Reforma y Democracia, 39, 33-50.

Peters, B. Guy. (2009) La Descentralización ante la Ineficiencia del Gobierno en Revista de Administración Pública, 41-1, 13-32.

Quah, Jon S.T. (2010). Public Administration Singapur Style. U.K.: Esmeral Group Publishing.

Rey Hernández, Cesar A. (2008). El reto de la Gobernabilidad en la Educación Pública en Puerto Rico. Madrid: Taurus.

Santana, Leonardo; Santiago Zoraida, \& Rivera, Ángel. (2008). La Gobernanza Democrática en Caguas. San Juan: EMS Editores.

Santiago Caraballo, Yaritza. (2012, 2 de septiembre). Despidos en Puertos podrían afectar al país. El Nuevo Día, p. 21.

Shabbir, Cheema G., \& Rondinelli, Dennis A. (2007). Decentralizing Governance, Emerging Concepts and Practices. Washington: Brooking Institute.

Simon Herbert, A. (1947). Administrative Behavior. New York: Free Press.

Simon Herbert, A. (1997). Models of Bounded Rationality. Cambridge, MA: MIT Press.

Sorensen, Eva, \& Torfing, Jacob. (2003). Network Politics, Political Capital and Democracy en International Journal of Public Administration, 26 (6), 609-634.

Torres, Eneida, \& Pratts, Saúl J. (Eds.) (2013). La Nueva Gobernanza para Puerto Rico. San Juan: Ediciones Puerto.

United Nations Development Program. (1990). Reconceptualizing Governance, Discussion Paper 2, New York.

Walsh, Stewart. (1992). Change in the Management of Public Services in Public Administration,

70, 499-518. 